\title{
Before translational medicine: laboratory-clinic relations
}

\author{
Michael Worboys ${ }^{1} \cdot$ Carsten Timmermann $^{1} \cdot$ Elizabeth Toon $^{1}$
}

Accepted: 11 November 2020 / Published online: 29 March 2021

(C) Springer Nature Switzerland AG 2021

\section{Introduction}

Translational Medicine (TM) was a term coined in the late 1990s that has enjoyed great currency across medicine and in health policy. An influential 2008 editorial in the British Medical Journal characterised TM as a process: the steps involved in getting a new remedy from the laboratory bench to the bedside as efficiently as possible. TM is then about the movement of ideas, materials and technologies from research laboratories, through evaluation and trials, to routine clinical application (Lean et al. 2008). But TM was never just a descriptive term, rather it was campaigning slogan. TM's champions and adopters wanted rapidly to accelerate the move from bench to bedside, either by more focused translational activities, or the removal of obstacles holding up different parts of the process. An important part of their message was that TM was new and that it would bring transformative patient benefits. Old relations between bench and bedside were said to have been bureaucratic, inefficient, and slow, with particular complaints about the stifling of innovation in pharmaceuticals, and this stagnation was said to threaten continued medical progress in alleviating suffering and saving lives. Thus, TM had moral power. Who could object to a programme that promised to advance disease prevention and treatment, reducing morbidity and mortality?

This Topical Collection explores bench to bedside relations in the half-century before the arrival of TM. The two key questions addressed are: How new was TM? How is it best to characterise bench-to-bedside relations in the period 1950-2000?

The second half of the twentieth century saw major changes in the practices and the self-understandings of 'scientific medicine' and its relation to clinical medicine.

Michael Worboys

michael.worboys@manchester.ac.uk

1 Centre for the History of Science, Technology and Medicine, University of Manchester, Manchester M13 9PL, UK 
In many ways, the post-1945 years intensified patterns first seen in the last quarter of the nineteenth century, when developments in the laboratory sciences of physiology, bacteriology, immunology and pathology brought advances in the understanding, prevention and treatment of disease (Cunningham and Williams 1992). Progress continued in the early decades of the twentieth century, with transformative innovations such as insulin, sulphonamides, BCG vaccine, and radium (Weatherall, 1992). Medical, scientific, and public expectations grew even higher after the Second World War, prompted by the development of penicillin in medicine and a host of innovations in other spheres, including radar, the jet engine, rocketry, DDT, computers, and the atomic bomb (Cooter and Pickstone 2000).

These hopes for further and faster science-led innovations was epitomised in Vannevar Bush's phrase - "Science the Endless Frontier" (Pielke 2010; Leyden and Menter 2018). Governments, corporations and philanthropic agencies across the world exponentially increased their investment in "science," or as it was then styled "R\&D" - research and development. Much of the increase was for military R\&D, which escalated the power of weapons and the sophistication and range of delivery systems. Non-military R\&D also delivered, as research laboratories, product and process engineers, and marketing and sales produced innovations as wide-ranging as passenger jet engines, semiconductors, mainframe computers, plastics and other synthetic chemicals, and so on.

Medicine too was paradigmatic of the achievement of the "Endless Frontier." Building on the success of penicillin, pharmaceutical companies created an "Antibiotic Revolution" (Kingston 2000). This prompted investments in drugs for other classes of disease, and successes followed with new vaccines, diagnostics, and treatments for chronic and degenerative diseases. Other areas of medicine also saw advances, for example in medical technologies, cancer treatments and a range of highly interventive surgical procedures that left no organ in the body untouched. Statistical methods, first developed as an aid to experimental research, were extended into clinical trials and meta-analysis, and these sophisticated forms of medical empiricism became influential in directing practice. The result, at least in industrialised countries, though unevenly across society, was a fall in mortality, especially in the over 70 years of age.

While the overall picture in medicine was positive, there were problems. Thalidomide provided the most devastating example of inadequate testing of new drugs and their overuse. In many diseases there were relatively modest gains, as with the largest single cause of death - lung cancer (Timmermann 2013). Increased longevity in many cases meant more people lived with chronic, medically-managed conditions. A slowdown in the rate of introduction of new antibiotics, which had symbolised the new dawn in medicine and even promised the eradication of many infectious diseases, led to a belief among some observers that there were diminishing returns in medical R\&D (Carmichael and Begley 2010). For example, there were few effective anti-viral drugs. The relative dearth of new antibiotics became an issue as bacterial resistance to existing antibiotics increased. Why were there fewer new antibiotics? Several reasons were given. Researchers had exhausted the established pathways for the chemical inhibition and destruction of bacteria. New avenues were needed. Antibiotics were still the largest class of drugs by sales value, but companies had a 
growing interest in treatments for chronic, non-infectious conditions. The pharmaceutical industry argued that one reason for lack of investment was that drug development was hindered by over regulation. Protocols for testing and efficacy had been made more rigorous after the Thalidomide tragedy, and were further expanded with new clinical trial standards. Many groups across medicine and the pharmaceutical industry came up with metaphors for the situation: the bench-to-bedside "pipeline was blocked"; and that new drugs faced crossing "the valley of death" (Butler 2008). The key aim of TM, then, was to unblock, repair or shorten the pipeline, and find new ways to cross the valley of death.

While TM was said to be inspired by problems in the pharmaceutical industry, the term and its aims were soon taken up in every medical specialism and then moved into the social sciences, education and engineering (Hudgins and AllenMeares 2000).In this Special Collection, Anne Krueger, Barbara Hendriks and Stephan Gauch (2019) discuss the immediate origins and the emergence of TM, linking it to wider interest in translational research. Their focus is on the multiple meanings of TM and related terms, and how they were used in the rhetorical politics of contemporary medicine. While Krueger, Hendriks and Gauch are, on the face of it, just considering how different groups met the challenge of "deficits in the diffusion, reception, and application of new medical knowledge," the authors also argue that what was really at stake was redefining place of the laboratory - their term is "(bio) medical science" - in early twenty-first century health care and public health.

Mark Robinson (2020) argues that TM - his term is Translational Science and Medicine (TSM) was a genuinely new development, and that it was contingent upon a deeper and more profound financial transformation in medicine. Focusing on the United States, he points to the creation by the state and Big Pharma of new structures and systems that "externalize the cost and risks of early-stage R\&D for pharmaceutical companies, source new investment opportunities for venture capitalists, and [enable] the more efficient and organized commercialization of academic science."

The remaining three articles in this Collection are three historical case studies of bench to bedside translations in the second half of the twentieth century. Worboys and Toon (2019) look afresh at cortisone, an iconic medical innovation. Unusually, the discoverers of cortisone were awarded a Nobel prize within months of its announcement, such was the expectation that it would transform the treatment of rheumatoid arthritis and other chronic inflammatory diseases. But early clinical uses soon showed that risks were often greater than benefits, quickly stimulating a search for safer, more effective alternatives. Worboys and Toon tell a story of multiple and complex translations of different drugs from laboratory to bedside. Cortisone stimulated the innovation of a whole new class of drugs - corticosteroids, which being more effective, safer and cheaper, eclipsed cortisone itself in the treatment of rheumatoid arthritis.

Timmermann (2020) explores how interferon, a major medical discovery of the 1950 s and 60s, moved from the laboratory to the clinic, specifically focusing on how Hoffman La Roche (Roche) brought Roferon A to market as a cancer treatment in 1986. Roche, as he shows, built up its capability and capacity in molecular biology in the 1960s, expecting the nascent science would eventually lead to 
clinical application. What was critical in the development of Roferon was linking of this expertise with the existing scientific, technical, regulatory, process and product development know-how in the company. Timmermann uses this case to argue that "mobilization" rather than "translation" best captures the process of the drug's development.

The final article, by Worboys and Toon (2020) and focusing on the work of William Copeman in rheumatology, further widens the examination of TM's history to explore forms of translation other than bench to bedside. Copeman was at the forefront of the introduction of cortisone in Britain, but he had a longer and wider role in bringing transformative benefits to arthritis sufferers. As a leading consultant, he had endeavoured to translate and spread best practice in several ways: to better instruct already qualified general practitioners; to improve training in rheumatology in medical education; to develop rheumatology as a specialism; and to better educate the public. The story of Copeman's work and role in British rheumatology shows the importance of looking beyond the laboratory as the source of medical progress and patient benefits.

In conclusion, all our authors make clear the need to avoid thinking about "translation" as a single step and TM as an entity. Rather, TM involves many translations of many types and is best approached as a series of processes - material and social. The authors also show that the many moves from bench-to-bedside involved more than M - "medicine." For example, Timmermann's study demonstrates that the development of Roferon included academic research, corporate research, animal testing, process and product development, marketing, and different areas of "medicine." In short, the Collection shows the need to unpack both the "T" and "M" in TM.

What answers do our authors give to the two questions set out at the beginning of this Introduction. First, how new was TM? Krueger, Hendriks \& Gauch and Robinson show that the rhetoric and the policy-push of TM were novel, however, the historical case-studies of cortisone and Roferon show continuities between now and then. Thus, they implicitly question Robinson's claim that TM signalled the arrival of a new political economy of medicine, with the commercialisation of academic research. That said, one consequence of the impact of TM on research policy and institutional structures has been the prioritising and privileging of the laboratory as the primary source of transformative change in medicine. This has led to the neglect, in policy deliberations and prescriptions, of other sources of change, for example, the types of "translation" that Worboys and Toon detail in their article on William Copeman.

Second, how is it best to characterise bench-to-bedside relations in the period 1950-2000? The term bench-to-bedside tends to be portrayed as linear and teleological; hence, the popular metaphor of the "pipeline." The case studies of cortisone and Roferon show that in pharmaceuticals, bench-to-bedside depended on complex interactions between researchers, developers, regulators, marketers, clinicians, patients, biology, and diseases. Perhaps a better metaphor is a road network and a journey. Thus, there are different vehicles, choices of routes with different speeds, congestion, stop-starts, dead ends, roundabouts and getting lost. Road networks are not stable: new vehicles come along, new roads, new rules, and new destinations. 
In this vein, Timmermann's suggestion of "mobilisation" is productive, as it better captures complexity, choices and agency. It opens up new research possibilities, with the requirement to study the many actors and actants involved, with attention to power and economic factors in negotiations and outcomes. Adopting "mobilisation" necessitates researchers exploring neglected sources, such as company records, and to interrogate material and social practices at every stage and level.

Acknowledgements We would like to thank the Wellcome Trust (Grant No. WT 092782) for their support

\section{References}

Butler, D. (2008). Crossing the valley of death. Nature, 453, 840-842.

Carmichael, M., \& Begley, S. (2010). Desperately seeking cures: How the road from promising scientific breakthrough to real-world remedy has become all but a dead end. Newsweek, 155(22), 38-43.

Cohen, J. (1993). Task force to speed drug pipeline. Science, 262(5140), 1641-1642.

Cooter, R., \& Pickstone, J. (Eds.). (2000). Medicine in the twentieth century. Amsterdam: Harwood.

Cunningham, A., \& Williams, P. (Eds.). (1992). The laboratory revolution in medicine. Cambridge: Cambridge University Press.

Hudgins CA, Allen-Meares P (2000) From the Editor, Journal of Social Work Education, 36(1), 2-5 https://doi.org/10.1080/10437797.2000.10778985

Kingston, W. (2000). Antibiotics, invention and innovation. Research Policy, 29(6), 679-710.

Krueger, A. K., Hendriks, B., \& Gauch, S. (2019). The multiple meanings of translational research in (bio)medical research. History and Philosophy of the Life Sciences, 41, 57. https://doi.org/10.1007/ s40656-019-0293-7.

Leyden, D. P., \& Menter, M. (2018). The legacy and promise of vannevar bush: Rethinking the model of innovation and the role of public policy. Economics of Innovation and New Technology, 27(3), 225-242. https://doi.org/10.1080/10438599.2017.1329189.

Pielke, R. (2010). In retrospect: science-The endless frontier. Nature, 466, 922-923. https://doi.org/10. $1038 / 466922 \mathrm{a}$.

Robinson, M. (2020). Why translational medicine is, in fact, "new", why this matters, and the limits of a predominantly epistemic historiography. History and Philosophy of the Life Sciences, 42, 34. https:// doi.org/10.1007/s40656-020-00324-z.

Timmermann, C. (2013). A history of lung cancer: The recalcitrant disease. Basingstoke: Palgrave Macmillan.

Timmermann, C. (2019). How to produce 'marketable and profitable results for the company': From viral interference to Roferon A. History and Philosophy of the Life Sciences, 41, 30. https://doi.org/10. 1007/s40656-019-0268-8.

Weatherall, M. (1990). In search of a cure: A history of pharmaceutical discovery. Oxford: Oxford University Press.

Worboys, M., \& Toon, E. (2019). Special issue-before translational medicine: Laboratory clinic relations lost in translation? Cortisone and the treatment of rheumatoid arthritis in Britain, 1950-1960. History and Philosophy of the Life Sciences, 41, 54. https://doi.org/10.1007/s40656-019-0269-7.

Worboys M, Toon E, (2020) Not only laboratory to clinic: the translational work of William S. C. Copeman in rheumatology. History and Philosophy of the Life Sciences 42, 35. https://doi.org/10.1007/ s40656-020-00330-1

Publisher's Note Springer Nature remains neutral with regard to jurisdictional claims in published maps and institutional affiliations. 